\title{
Middle Aged Man with Bilateral Lower Limb Weakness and Non-Traumatic Fractures: Case of Hypophosphatemic Osteomalacia
}

\author{
Ashfaque Memon* and Amjed Khamis \\ Department of Endocrinology/General internal medicine, Letterkenny university hospital, Ireland
}

Submission: April 21, 2017; Published: June 30, 2017

*Corresponding author: Ashfaque Memon, Senior Registrar General Internal Medicine, Sligo University Hospital, Republic of Ireland, Tel: +353851464517; Email: dr_agha80@hotmail.com

\section{Abstract}

A 58 year old man was referred by an Orthopaedic surgeon to endocrinology services for an opinion over fragile bones. The patient had a long history of weakness in both legs and recurrent non-traumatic fractures of long bones. His baseline work up showed low phosphate, low-normal calcium, high Alkaline phosphatase (Alk.P), and normal Vitamin D, Parathyroid Hormone (PTH) and renal function. He had significant weakness in his proximal limb muscles and was unable to walk without crutches. Initially he was treated with bisphosphonates under the assumption that his high Alk.P was due to Paget's disease. Looking at the persistence of symptoms and low phosphate levels, further investigations were done which lead to the diagnosis of Hypophosphatemic Osteomalacia. High doses of phosphate and Vitamin D supplements were started, which brought clinical and biochemical improvement within few months, and by twelve months patient was able to walk independently.

\section{Introduction}

Hypophosphatemia is one of the most underrated biochemical disorders and is often ignored in the clinical practice. Hypophosphatemic osteomalacia is a disabling bone disorder; though literature about this uncommon and potentially curable form of osteomalacia is not scarce but a large majority of clinicians is unaware about this potentially curable disorder. This case report emphasizes the importance of investigating the chronic hypophosphatemia especially in the settings of muscle weakness and bone pain.

\section{Case Presentation}

A 58 years old man known case of Hypertension, Ischemic heart disease, and dyslipidaemia was living otherwise normal life without assistance until 2009, when he developed mild pain in his right lower leg and foot. It progressively got worse with the development of weakness in both legs. His mobility was significantly affected that he became unable to walk without crutches. He didn't seek medical attention that time. In 2011, he was brought into the emergency department of Letterkenny University Hospital with sudden onset of severe pain in Left hip. X.ray Pelvis showed a new left neck of femur (NOF) fracture along with an old unhealed fracture of right NOF. History revealed that he was bending down to pick up some stuff from ground when he suddenly developed this pain. Both fractures were managed with screw fixation.

In 2012 he was readmitted due to severe pain in right hip after a minor fall. X.ray confirmed the Right hip fracture, which was managed with intramedullary hip screw (IMHS). He was readmitted in 2014 with increasing pain in right hip and required total hip replacement. This time case was referred for Endocrinology review as orthopaedic surgeon was concerned about the strength of the bones and wondering if there is any underlying medical problem.

On examination patient appeared a healthy gentleman using crutches for walking. There was no any gross deformity in his limbs, skull and chest. He had no hearing impairment, cranial nerves, sensations and reflexes were normal. Power was reduced in legs mainly in proximal muscles. It was obvious that patient had great difficulty to come out of the chair. He was on Perindopril 5mg once daily, Atorvastatin $20 \mathrm{mg}$ once daily, Indapamide $2.5 \mathrm{mg}$ once daily, aspirin $75 \mathrm{mg}$ once daily. His previous work up showed hypophosphatemia, hypocalcaemia, 
high Alkaline phosphatise (Alk.P), normal Vitamin D and parathyroid hormone (PTH) levels (Table 1).

Table 1: Bochemistry at the time of endocrinology referral.

\begin{tabular}{|c|c|}
\hline Corrected Ca & $2.08[2.15-2.50]$ \\
\hline Phosphate & $0.48[0.81-1.45]$ \\
\hline Alk. P & $186[40-129]$ \\
\hline PTH & $54[15-65]$ \\
\hline Vit D & 68 \\
\hline Creatinine & 70 \\
\hline Urea & 5.9 \\
\hline Na & 131 \\
\hline Potassium & 3.8 \\
\hline LFTs & Normal \\
\hline
\end{tabular}

He had a bone scan done in 2011, showed increased osteoblastic activity and diffuse uptake of technetium contrast. Dual energy X.ray absorptiometry (DEXA) scan done in 2012, was largely normal except mild osteopenia at lumbar spine. MRI both hips was done in 2012 to check the post operative stability of the hip screws, didn't show any bone deformity. A differential including Paget's disease, Fanconi syndrome, Vitamin D resistant osteomalacia and Myeloma was made and patient was started on calcium and vitamin D (colicalciferol) supplements.

After six months both clinically and biochemically no improvement was noticed with the persistence of pain and weakness in the legs and presence of hypophosphatemia, high Alk.P, low normal calcium and normal vitamin D levels (Table 2). A six months course of bisphosphonates was started as Paget's disease was still on the top of differential. Further work up including skeletal survey, Computed tomography (CT) scan of pelvis and repeat bone scan were arranged. Skeletal survey showed hyperostosis frontalis interna, healed fractures of rib cage and united fracture of proximal right femur but no any feature suggestive of Paget's disease or myeloma. CT scan pelvis showed extensive abnormality in the bone marrow attenuation suggestive of insufficiency fractures of the sacrum. Bone scan again showed significant abnormal osteoblastic activity.

Table 2

\begin{tabular}{|c|c|c|c|c|c|c|}
\hline & Corrected Ca & Phosphate & Alk. P & Vit D & PTH & Medications \\
\hline $2 / 5 / 2014$ & 2.25 & 0.65 & 218 & 68 & 54 & Nil \\
\hline $3 / 5 / 2014$ & 2.08 & 0.48 & 186 & & & Calcium Vit D \\
\hline $12 / 6 / 2014$ & 2.2 & 0.51 & 378 & & & Calcium Vit D \\
\hline $1 / 4 / 2015$ & 2.36 & 0.63 & 437 & 54 & & $\begin{array}{c}\text { Bisphosphonates+ Sandoz Phosphate } 01 \text { tablet + } \\
\text { Calcium Vit D }\end{array}$ \\
\hline $28 / 06 / 15$ & 2.12 & 0.48 & 336 & 51 & & $\begin{array}{c}\text { Bisphosphonates stopped, Phosphate dose increased } \\
\text { + Calcium Vit D }\end{array}$ \\
\hline $5 / 9 / 2015$ & 2.19 & 0.46 & 271 & & & Phosphate dose increased + Calcium Vit D \\
\hline $2 / 12 / 2015$ & 2.06 & 0.87 & 661 & 41 & & $\begin{array}{l}\text { Bisphosphonates restarted + same dose Phosphate + } \\
\text { calcium Vit D }\end{array}$ \\
\hline $18 / 03 / 16$ & 2.08 & 0.41 & 323 & 34 & 80 & $\begin{array}{c}\text { Change vit D to One alpha + continue Bisphosphonates } \\
\text { and Phosphate tablets }\end{array}$ \\
\hline $9 / 6 / 2016$ & 2.21 & 0.51 & 248 & 34 & & $\begin{array}{l}\text { Bisphosphonates stopped, One alpha dose increased. } \\
\text { Same dose phosphate }\end{array}$ \\
\hline $1 / 9 / 2016$ & 2.19 & 0.46 & 321 & 33 & 54 & $\begin{array}{c}\text { Increase Phosphate dose, increase One alpha, increase } \\
\text { Calcium tablets }\end{array}$ \\
\hline
\end{tabular}

A 24 hours urinary calcium and phosphate showed normal urinary calcium and elevated phosphate levels in the presence of severe hypophosphatemia. His biochemical abnormalities largely remained unchanged with persistence of hypophosphatemia and high Alk.P with normal vitamin D and PTH levels. It was now believed that hypophosphatemia is the main reason behind all the problems with bone. Phosphate supplements were started at high doses and colicalciferol was changed to alphacalcidol. After nearly twelve months of receiving high dose phosphate supplements along with vitamin D, patient started showing improvement. His pain was completely subsided and weakness gradually resolved to the extent that he stopped using crutches and could mobilize independently (Table 2).

\section{Discussion}

Osteomalacia is a rare disorder of bone mineralization caused by a deficiency of calcium, phosphorus or Vitamin D, which results in inadequate or delayed mineralization of osteoid in bone tissue [1]. In children, this condition is called as rickets and is associated with growth plate abnormalities in addition to delayed mineralization [2].

Hypophosphatemic rickets/osteomalacia (HRO) is a rarest type of osteomalacia, characterized by low serum phosphate levels leading to impaired mineralization of bone matrix [3]. In children it usually causes disproportionate short stature and classical features of rickets, and in adults it results in bone pains, proximal myopathy and enthesopathy [4]. 
Despite that osteomalacia occurs due to the individual or combined deficiency of Calcium, Phosphate and vitamin $D$, these disorders and their causes should be categorized separately. Hypocalcaemia and vitamin D deficiency stimulates the PTH release and produces the characteristic features of bone resorption on imaging. In contrast hypophosphatemia does not exert any stimulatory effect on PTH, hence features of bone resorption are usually absent [2].

Fibroblast growth factor 23 (FGF 23) also called as phosphaturic factor is produced by osteoblasts and osteocytes, plays vital role in the phosphate homeostasis. It inhibits the re absorption of phosphate in kidneys to avoid excess phosphate accumulation in the blood. Certain genetic and non-genetic disorders cause abnormal activation of FGF 23, which result in excessive urinary loss of phosphate and severe hypophosphatemia.

Dietary deficiency of phosphate is very rare. Hypophosphatemia occurs either due to excessive urinary loss, impaired intestinal absorption or transcellular shift of phosphate [5]. Hyperparathyroidism, Fanconi syndrome, diuretics, antibiotics (Aminoglycosides, tetracycline), Bisphosphonates and Mannitol increase urinary loss of phosphate. Genetic causes of hypophosphatemia such as X. Linked hypophosphatemia (XLH), Autosomal dominant Hypophosphatemic rickets (ADHR), and Autosomal recessive hypophosphatemic rickets (ARHR) are rare, yet important causes of excessive urinary excretion of phosphate resulting in severe hypophosphatemia. The hallmark of these genetic disorders is the excessive activity of FGF23.

Hypophosphatemia due to excessive activity of FGF 23 is also seen in non-genetic diseases such as tumour induced osteomalacia (TIO) and fibrous dysplasia. Hypophosphatemia due to impaired intestinal absorption occurs due to Vitamin D deficiency, alcoholism, phosphate binders and antacids. Transcellular shift of phosphate produces acute and usually transient hypophosphatemia; seen in refeeding syndrome, after glucose or insulin infusion, salicylate poisoning, hyperventilation and respiratory alkalosis [5]. XLH, ADHR, ARHR and TIO are collectively termed as Adult-onset hypophosphatemic vitamin D-resistant osteo-malacia (AHVDRO). The characteristic feature of these disorders is, increased activity of FGF 23, [6].

These disorders cause impaired bone mineralization, osteomalacia or rickets and insufficient active vitamin D production. Activating mutations of FGF-23 and inactivating mutations in the PHEX gene $[7,8]$ resulting in abnormal activation of FGF 23 have been implicated in the pathogenesis of these disturbances. Interestingly, patient shows variability in age of clinically evident disease [9]. In XLH symptoms usually start during childhood. However, some patients can have a delayed onset of phenotype, with normophosphatemia and normal growth during childhood, to be followed by onset of hypophosphatemic osteomalacia in adulthood [6].
So in general, clinical presentation varies with the age and underlying subtype of AHVDRO. Younger patients present with growth retardation and bone deformities and adults suffer from bone pain, proximal myopathy and non traumatic fractures. ADHR also shows significant variation in the age of clinical manifestation; disease may appear only in adolescence with normal childhood. When manifested after the puberty, the most common characteristics of ADHR are bone pain, pseudofractures and muscle weakness [9].

The characteristic biochemical abnormalities seen in AHVDRO is, hypophosphatemia, normal or low serum calcium, high or high normal Alk.P, low or inappropriately normal vitamin D, normal PTH level and low maximum tubular reabsorptive capacity for phosphorus/glomerular filtration rate (TmP/GFR).

Radiologic manifestations in younger patients are seen in tibia, distal femur, radio and ulna, and reflect loss of definition and widening. In adults diffuse bone sclerosis and welldefined enthesophytes can be seen. Insufficiency fractures are characteristic finding; typically occur over concave aspect of the proximal femur and tibia, pubic rami, ribs, and the lateral aspect of the scapula [10]. Skeletal survey and isotope bone scan help in detecting insufficiency fractures and osteoblastic activity respectively.

Work up for AHVDRO should include Protein electrophoresis, Tumor markers (CEA, 15.3, 19.9,125, Alphglycoprotien) Gastroscopy, Celiac antibodies, Skeletal survey, Abdominal US/ CT, Bone scan, DEXA scan, 24 hours urine Phosphate and Calcium and Chromosomal studies for FGF 23/PHEX gene mutations.

Clinical treatment of hypophosphatemic rickets aims at identifying the underlying cause and treating the hypophosphatemia to minimize the metabolic disturbances and bone deformities. Patients with excessive activity of FGF 23 require higher doses of Phosphate and Calcitriol, since no any treatment can alter the effect of FGF23 on the kidney [11]. Phosphate salts are given in doses of elemental phosphorus ranging from $20-40 \mathrm{mg} / \mathrm{kg}$ per day in four divided doses. Calcitriol dosing is usually $20-30 \mathrm{ng} / \mathrm{kg}$ per day. In TIO, the goal of treatment should be complete resection of the tumor which allows correction of excess phosphaturic factor. High Doses of phosphate and vitamin D can cause GI disturbance, Diarrhoea, Nephrocalcinosis, Renal insufficiency, and Secondary (sometimes tertiary) hyperparathyroidism. Six monthly PTH level and one or two yearly renal ultrasound is recommended.

\section{Conclusion}

Our patient had hypophosphatemia, high Alk.P normal calcium, vitamin D and PTH levels. He had insufficiency fractures and fragile bones (impaired mineralization) with increased osteoblastic activity. He sustained multiple non traumatic fractures and suffered from significant muscle weakness with proximal myopathy. He required very high doses of 
Phosphate and vitamin Dand got excellent recovery. We are sure hypophosphatemia is the main reason for all his problems with bone and mobility.

\section{N.B-Genetic tests are pending}

\section{References}

1. Rosen, Clifford J (2008) Primer on the metabolic bone diseases and disorders of mineral metabolism. ( $7^{\text {th }}$ edn), American Society of Bone and Mineral Research, Washington, USA, p. 32

2. Pitt MJ (2002) Rickets and osteomalacia. In: Resnick D (Ed.), Diagnosis of bone and joint disorders. ( $4^{\text {th }}$ edn), Saunders, Philadelphia, USA, pp. 1901-1945.

3. Fukumoto S, Yamashita T (2001) Fibroblast growth factor (FGF)-23 and hypophosphatemic rickets/osteomalacia. Endocr J 48(6): 603610

4. Chan JC, Alon U, Hirschman GM (1985) Renal hypophosphatemic rickets. J Pediatr 106(4): 533-544.

5. Imel EA, Econs MJ (2012) Approach to the Hypophosphatemic Patient. J Clin Endocrinol Metab 97(3): 696-706.
6. deBeur SMJ, Levine MA (2002) Molecular pathogenesis of hypophosphatemic rickets. J Clin Endocrinol Metab 87(6): 2467-2473.

7. ADHR Consortium (2000) Autosomal dominant hypophosphataemic rickets is associated with mutations in FGF23. Nat Genet 26(3): 345348.

8. (1995) A gene (PEX) with homologies to endopeptidases is mutated in patients with X-linked hypophosphatemic rickets. The HYP Consortium. Nat Genet 11(2): 130-136.

9. Econs MJ, McEnery PT (1997) Autosomal dominant hypophosphatemic rickets/osteomalacia: Clinical characterization of a novel renal phosphate-wasting disorder. J Clin Endocrinol Metab 82(2): 674-681.

10. Hardy DC, Murphy WA, Siegel BA, Reid IR, Whyte MP (1989) X-linked hypophosphatemia in adults: prevalence of skeletal radiographic and scintigraphic features. Radiology 171(2): 403-414.

11. Harrell RM, Lyles KW, Harrelson JM, Friedman NE, Drezner MK (1985) Healing of bone disease in X-linked hypophosphatemic rickets/ osteomalacia. Induction and maintenance with phosphorus and calcitriol. J Clin Invest 75(6): 1858-1868.

\section{Your next submission with Juniper Publishers will reach you the below assets}

- Quality Editorial service

- Swift Peer Review

- Reprints availability

- E-prints Service

- Manuscript Podcast for convenient understanding

- Global attainment for your research

- Manuscript accessibility in different formats

( Pdf, E-pub, Full Text, Audio)

- Unceasing customer service

Track the below URL for one-step submission

https://juniperpublishers.com/online-submission.php 